\title{
Pilot experiment of oily cuttings thermal desorption and heating characteristics study
}

\author{
Xianyong Zhang ${ }^{1,2} \cdot$ Aiguo Yao $^{1}$
}

Received: 20 November 2017 / Accepted: 2 November 2018 / Published online: 16 November 2018

(c) The Author(s) 2018

\begin{abstract}
Thermal desorption disposal of oily drilling cuttings was tested on the developed medium sized experimental system. The thermal desorption unit adopted electromagnetic induction heating during continuous conveying of materials by double screws, and the handling capability was $250 \mathrm{~L} / \mathrm{h}$. Thermal desorption test at different temperatures $\left(300-550{ }^{\circ} \mathrm{C}\right)$ were carried out in conditions of residence times of $7 \mathrm{~min}$ and $12 \mathrm{~min}$ respectively. Total petroleum hydrocarbon (TPH) content of samples after treatment reduced to less than $1 \%$ when heating temperature up to $450{ }^{\circ} \mathrm{C}$, and the oil removal rate was about 95\%. The residual content of TPH dropped to $0.3 \%$ when heating temperature at $550{ }^{\circ} \mathrm{C}$ and residence time reached to $12 \mathrm{~min}$. The temperature distribution of the material in heating bed obtained by numerical simulation based on test operating conditions. A temperature rising lag area of materials in filling section of barrel was found when heating. The material temperature in this area was only about $55-65 \%$ of the setting value when residence time reach to 12 min, while the other areas temperatures could up to above $90 \%$, and the deviation between the material temperature and the setting value became obvious when the temperature is higher.
\end{abstract}

Keywords Oily cuttings $\cdot$ Thermal desorption $\cdot$ Induction heating $\cdot$ Pilot test $\cdot$ Temperature characteristics

\section{Introduction}

Oil-based drilling fluids have been widely used in oil and gas drilling because of its excellent properties of viscosity stability, heat-resistance, inhibition ability to shale and lubricating ability. The use of oil-based drilling fluids brings great convenience, but also produces oily drilling cuttings which belong to hazardous waste (Zhu et al. 2011; Siddique et al. 2017). Petroleum hydrocarbons in oily cuttings are the main components that are likely to seriously affect ecosystems such as soil and water on land (Siddique et al. 2017). Oily cuttings on offshore platforms are prohibited to discharge without innocent treatment for consideration of protecting marine ecological environment (Bakke et al. 2013).

Thermal desorption disposal of oily cuttings has attracted attention because of its advantages of high efficiency, less

Aiguo Yao

aiguo_yao@163.com

1 Faculty of Engineering, China University of Geosciences, Wuhan, Hubei, China

2 School of Mechanical Engineering, Yangtze University, Jingzhou, Hubei, China secondary pollution, strong adaptability of raw materials, and reusable of processed products (Jones et al. 2002; Stephenson et al. 2004; Júnior et al. 2017). For on-site continuous processing, heating mode and material carrier are two important technical links of the thermal desorption unit (TDU). Brandt Co. developed two basic types of thermal desorption units: the indirect fired rotary kiln type, and the screw or paddle type which used a heat transfer fluid (Pierce et al. 2006). The fuel for indirect fired is diesel or the recovered oil from oily cuttings, while the environmental regulatory agency might think that secondary pollution would be caused by combustion. The temperature carrying of the heat transfer fluid is limited, and the industrial heat transfer oil maximum operating temperature is usually around $350{ }^{\circ} \mathrm{C}$. This temperature is only marginally hot to remove oil from raw materials to an acceptable limit. The thermomechanical cuttings cleaner (TCC) is another type of thermal desorption system, which adopts frictional heating (Murray et al. 2008). The TCC has a hammer mill, which crushes cuttings and generates heat by friction during the process of hammering and crushing. The friction heat generated by the hammer mill can make the cuttings temperature up to $300{ }^{\circ} \mathrm{C}$. The oil phase with high boiling point might be difficult to 
remove due to the limited friction heating temperature, and the adaptability of materials is limited. Microwave heating of thermal desorption is another method that attracts more attention by researchers (Robinson et al. 2008; Falciglia and Vagliasindi 2015; Júnior et al. 2017). Microwave heating is a direct heating method with highly efficient, and the material is heated evenly. The absorption of microwave energy by materials affects the efficiency of liquid phases desorption. The physical and chemical properties of the materials and the dielectric constant of pollutants have great influence on microwave energy absorption (Falciglia et al. Falciglia and Vagliasindi 2015; Petri et al. 2017). Therefore, microwave heating has great selectivity for material composition. It is especially effective for the heating of polar compounds.

In continuous processing, the way of materials carrier is important. Fixed bed and fluidized bed are typical installations (Schmidt and Kaminsky 2001; Shen and Zhang 2003; Liu et al. 2008), which are generally considered suitable for laboratory research. Rotary barrel device (or rotary kiln) is an optional scheme for continuous processing of materials (Fortuna et al. 1997; Chen et al. 2006; Sun et al. 2017). The rotary barrel device usually fixes up the heating unit on the outer side, heating the material through heat conduction. The whole equipment is usually larger and the heating may not be efficient. On the other hand, continuous feeding and discharging are not very convenient because of the rotary kiln structure characteristic. Nickerson et al. designed a screw conveyor apparatus with hollow blades (Nickerson 2008; Whitney and Nickerson 2010). The structure of the hollow blade is used for conducting hot fluid and to heat the spiral blade. This way takes into account the continuity of material conveying, and the total heat transfer area is increased.
In drilling field, especially the offshore drilling platform, thermal desorption disposal of oily cuttings should be efficient and relatively smaller footprint of equipment. For continuous treatment, the residence time of material should be shorter, so that the length of TDU can be shortened. However, shorting the residence time of heating may be unfavorable to the effect of thermal desorption. On this condition, the heating efficiency becomes fairly important. The skid mounted pilot experimental installations have been built up by electromagnetic induction heating, and materials continuous conveying based on double screws conveying apparatus. The processing capacity of the TDU is about $250 \mathrm{~L} / \mathrm{h}$, and experiments were carried out and key process parameters were studied.

\section{Experimental installations}

The experimental system is mainly composed of the thermal desorption unit (TDU) and the post-processing system, as shown in Fig. 1. The core of the experimental system is the TDU, which includes feeder, heating and desorption system, discharging and cooling system, steam generator and air locks. Heating and desorption device uses double screws to transport material, and the heating source adopts super-audio frequency electromagnetic induction heating. Inductive coils are arranged in both the barrel and two screw shafts, and temperatures are controlled independently.

Thermal desorption should be carried out in an oxygen isolation environment, and air locks are installed at the feeding port and the discharge port of TDU. Before the experiment, steam is switched to device for purging and replacing

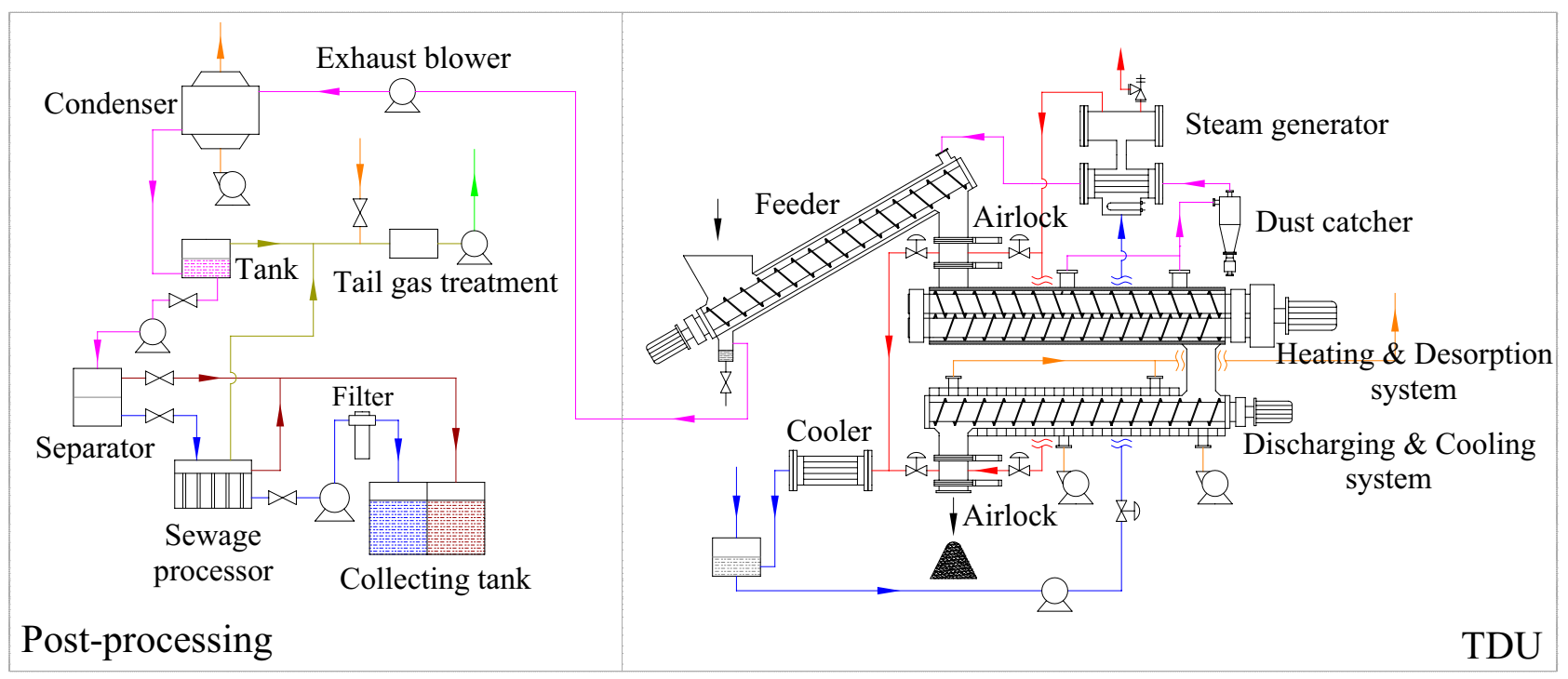

Fig. 1 Thermal desorption processing system

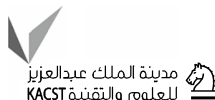


the air inside. The feeding mode is intermittent, a certain amount of materials entered the air lock storage barrel first, then steam is opened to purge and replace the air mixed with feeding, and then materials are transferred into thermal desorption barrel. The discharging process is similar to that of the feeding. The barrel and two screw shafts are heated rapidly by induction heating, and materials can be heated rapidly during conveying. The total heating time of the material, that is, the heating residence time, is equal to the material conveying time.

For safety consideration, the operating pressure in the TDU is maintained at atmospheric pressure, which is controlled by the exhaust blower installed at the tail of the vapors exhaust pipe. The vapors are timely pumped out of the TDU once the liquids evaporated. The residence time of vapors in the TDU is usually very short.

\section{Parameters setting and measuring}

Oily cuttings samples were obtained from shale gas well drilling site in CheXi, Yichang (China), and samples appearance was shown in Fig. 4a. The average TPH content of samples was $18.7 \%$ and the average water content was $9.4 \%$. The oil bearing component of samples was mainly diesel which was used as the base oil of the oil base drilling fluid.

The heating temperature affects the oil phase removal effect and energy consumption of the processing. Referring to evaporation temperatures of petroleum hydrocarbons, different heating temperatures of thermal desorption tests were set from 300 to $550{ }^{\circ} \mathrm{C}$. Two temperature sensors were arranged on inner wall of desorption barrel along axial direction. On each screw shaft, there were two temperature sensors located at feeding section and discharging section, respectively. Wall temperatures of heating bed were kept at the set value by temperature control system. Desorption barrel and spiral shafts were adopted electromagnetic induction heating independently, the heating rate was fast, and temperature control was very convenient. The set desorption temperature was roughly constant in the whole process, under the premise of sufficient heating power.

Residence time of heating is another important factor of thermal desorption. The average temperature of materials should be heated up to the set value of heating bed before discharging, and that should reach or exceed the liquids evaporation temperature during the residence time. Petroleum hydrocarbons are difficult to be completely removed if the residence time too short. However, the residence time is too long will lead to the waste of heating power. Since the material transferring and heating are synchronous, the heating residence time $(t)$ is equal to the conveying time in desorption barrel. The screw conveying length $(L)$ of TDU is $1950 \mathrm{~mm}$, and pitch of screw is $80 \mathrm{~mm}$. The residence time under different screw rotating speed is different, as shown in Table 1. Considering the material filling rate and residence time, the screw rotating speed $(n)$ range is $2.0-4.0 \mathrm{rpm}$.

The material feeding to TDU is intermittent due to the working characteristic of air locks. To metering convenience, one-time of $40 \mathrm{~kg}$ samples was fed to barrel at intervals of $5 \mathrm{~min}$, and the actual processing capacity was about $480 \mathrm{~kg} / \mathrm{h}$ according to the density $(1.8-2.1 \mathrm{~kg} / \mathrm{L})$ of oily cuttings. In the whole process of thermal desorption, the operating pressure in TDU was atmospheric pressure, which was real-time controlled by the exhaust blower.

The moisture content of samples was measured by mass difference under $105^{\circ} \mathrm{C}$ drying condition. The oil-bearing component of material is not a single compound, and the method of soxhlet extraction was used to measure the residual TPH content of treated samples. Using petroleum ether $\left(90{ }^{\circ} \mathrm{C}\right)$ as extraction solvent, and TPH content was measured by mass difference method.

\section{No-load preheating of device}

Desorption device should be preheated to setting temperature before the first feeding. According to the weight of desorption device, the preheating needs a certain amount of time. The relationship of preheating time, temperature change of heating bed and heating power is shown in Eq. (1). ' $\mathrm{P}_{0}$ ' is the preheating power; and ' $\mathrm{t}$ ' is the preheating time; ' $\mathrm{T}_{0}$ ' and ' $\mathrm{T}$ ' are the heating bed initial temperature and heated temperature, respectively; ' $m$ ' is the weight of device; ' $\mathrm{C}$ ' is the specific heat capacity of the metal material of heating bed. The device is made of carbon steel, which specific heat capacity variation is not obvious with temperature changes, and treated as a constant. As known from Eq. (1), there is a linear relationship between energy consumption and temperature change.

$P_{0} t=m C\left(T-T_{0}\right)$

The measurement results of the temperature of device changed from room temperature to the prescribed temperature are shown in Fig. 2. The barrel heating power was

Table 1 Residence times of materials in desorption barrel (constant handling capacity of $250 \mathrm{~L} / \mathrm{h}$ )

\begin{tabular}{llc}
\hline Screw speed $(n / \mathrm{rpm})$ & Filling coefficient $(\psi)$ & $\begin{array}{l}\text { Residence } \\
\text { time }(t / \mathrm{min})\end{array}$ \\
\hline 4.0 & 0.22 & 6.1 \\
3.5 & 0.25 & 7.0 \\
3.0 & 0.30 & 8.1 \\
2.5 & 0.35 & 9.8 \\
2.0 & 0.44 & 12.2 \\
\hline
\end{tabular}




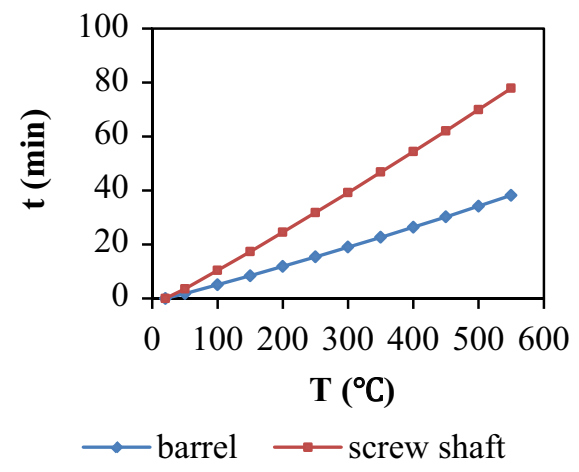

Fig. 2 Pre-heating time of no-load device

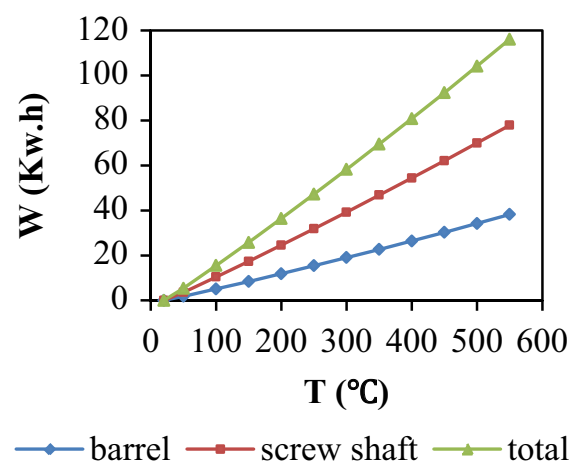

Fig. 3 Energy consumption of device pre-heating

$60 \mathrm{~kW}$ and each screw shaft heating power was $30 \mathrm{~kW}$, and maximum temperature of device increased to $550{ }^{\circ} \mathrm{C}$. Heating to the same temperature, time consumes of the screw shaft was about two times of that of the barrel. Figure 3 presents energy consumptions of device heating to different setting temperatures. From room temperature heating to $550{ }^{\circ} \mathrm{C}$, total energy consumption of no-load device was about $120 \mathrm{kWh}$.

\section{Thermal desorption test results and discussions}

After the heating bed walls (inner wall of the barrel and outer surface of screw shafts) were preheated to the set temperature, then start feeding, and kept the heating bed walls temperature constant during materials conveying. Being treated by thermal desorption, samples of oily cuttings became greyish white solid slag, as shown in Fig. 4b.

Thermal desorption results of samples at different temperatures are shown in Fig. 5. After disposing, TPH content of solid slag was reduced to less than $1 \%$ when desorption temperature up to $450{ }^{\circ} \mathrm{C}$. In conditions that the temperature increased to $550{ }^{\circ} \mathrm{C}$ and residence time reached to $12 \mathrm{~min}$, TPH content of solid slag could be dropped to $0.3 \%$. There is still a small amount of residual oil in solid slag. This residual oil removal may require higher temperature or longer residence time.

It can be seen from Fig. 5, the temperature influence on oil removal is obvious in condition of the same residence time. The temperature should reach to the liquids final distillation temperature before materials discharging. The final distillation temperature of diesel is about $370{ }^{\circ} \mathrm{C}$ (that of heavy diesel is about $410^{\circ} \mathrm{C}$ ), according to the temperature of diesel distilling from crude oil. To completely remove the oil phase from drilling cuttings, the material temperature should be over $410 \mathrm{C}$. The test results show that the oil removal rate is about $95 \%$ when the treatment temperature reaches to $450{ }^{\circ} \mathrm{C}$.

Comparing results of Fig. 5a, b, it can be concluded that the increase of residence time at the same set heating temperature can improve oil removal effect. The energy (a)

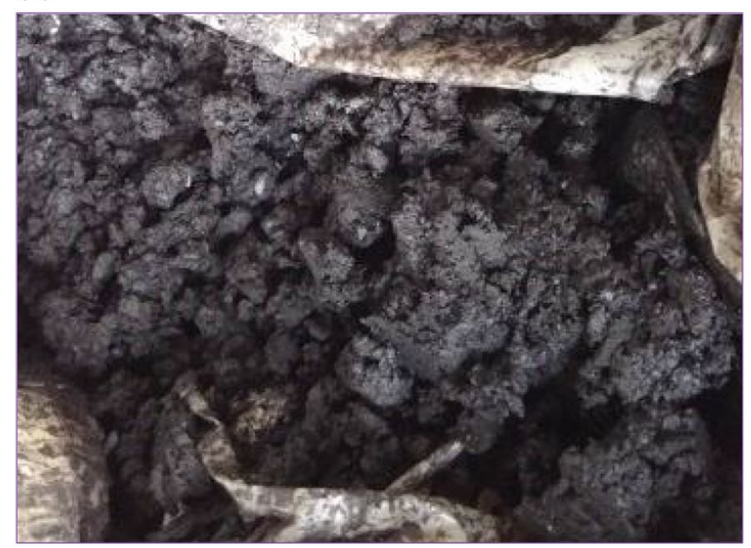

(b)

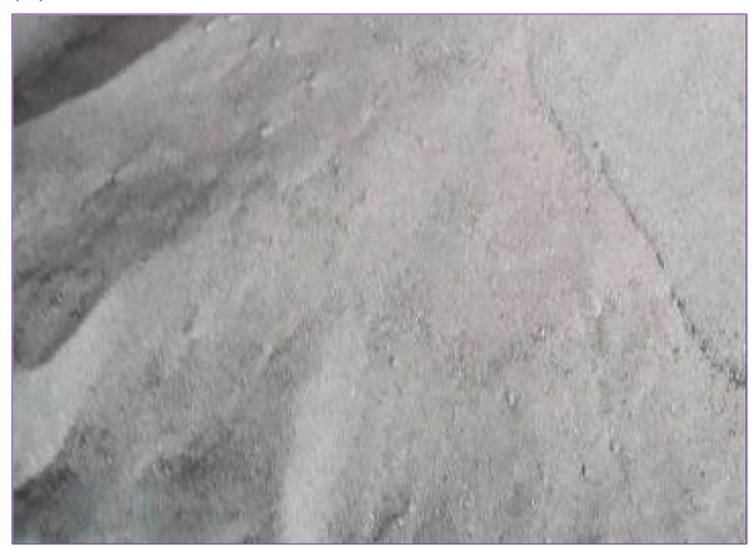

Fig. 4 Samples appearance (raw samples as shown in $\mathbf{a}$; samples being treated as shown in $\mathbf{b}$ ) 
Fig. 5 THP content and removal rate of samples after disposal (conditions of figure a: screw shaft rotation speed of $3.5 \mathrm{rpm}$ and corresponding residence time is $7 \mathrm{~min}$; conditions of figure b: screw shaft rotation speed of $2.0 \mathrm{rpm}$ and corresponding residence time is about $12 \mathrm{~min}$ ) (a)

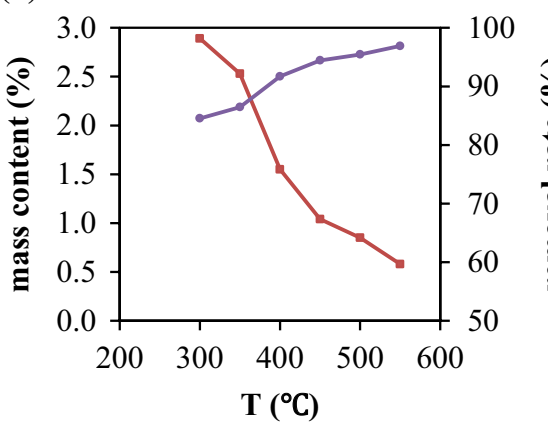

$\longrightarrow$ TPH content $\longrightarrow$ TPH removal rate (b)

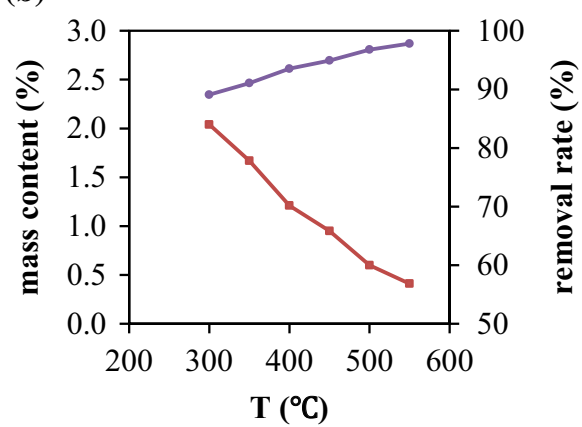

TPH removal rate transferred from hot walls to the material increases with the extension of residence time. Evaporation of liquids requires absorption of heat, and the liquid phase evaporates more thoroughly with the increasing of energy obtained.

For continuous conveying and heating, increasing the conveying length or decreasing the conveying speed can increase the heating residence time, while extending the conveying length will increase the space size of the equipment. Long equipment size is unfit for skid mounted design and is difficult to adapt to offshore platform. The heating temperature and residence time should be reasonably chosen to meet good disposal effect in limited equipment footprint.

\section{Temperature characteristics of materials}

The oil removal effect of the sample was obtained through experiments in the condition of different heating bed temperature. However, during the heating, the temperature distribution of material layer was difficult to be detected by experiments. To further study the variation of material internal temperature, numerical simulation was used to obtain it.

In double screw conveying, the material has a certain filling rate in the conveyor. The distribution of materials in desorption device is shown in Fig. 6. The inner wall of barrel and the outer wall of each screw shaft were set of constant temperature (temperature boundary condition) according to arrangement structures of the electromagnetic induction coil, and setting values were the heating temperature. The transient solution method was adopted, and initial temperature of material was the measured value in TUD feeding port. All thermodynamic parameters are taken at atmospheric pressure, according to the operating pressure condition of TUD.

To verify the validity of the numerical simulation, values of the average material temperature by simulation and that by test are compared, and Fig. 7 presents the comparison results. ' $\mathrm{T}_{\mathrm{s}}$ ' is the set heating temperature and ' $\mathrm{T}_{\mathrm{md}}$ ' is the material temperature at TDU discharging port. Simulated
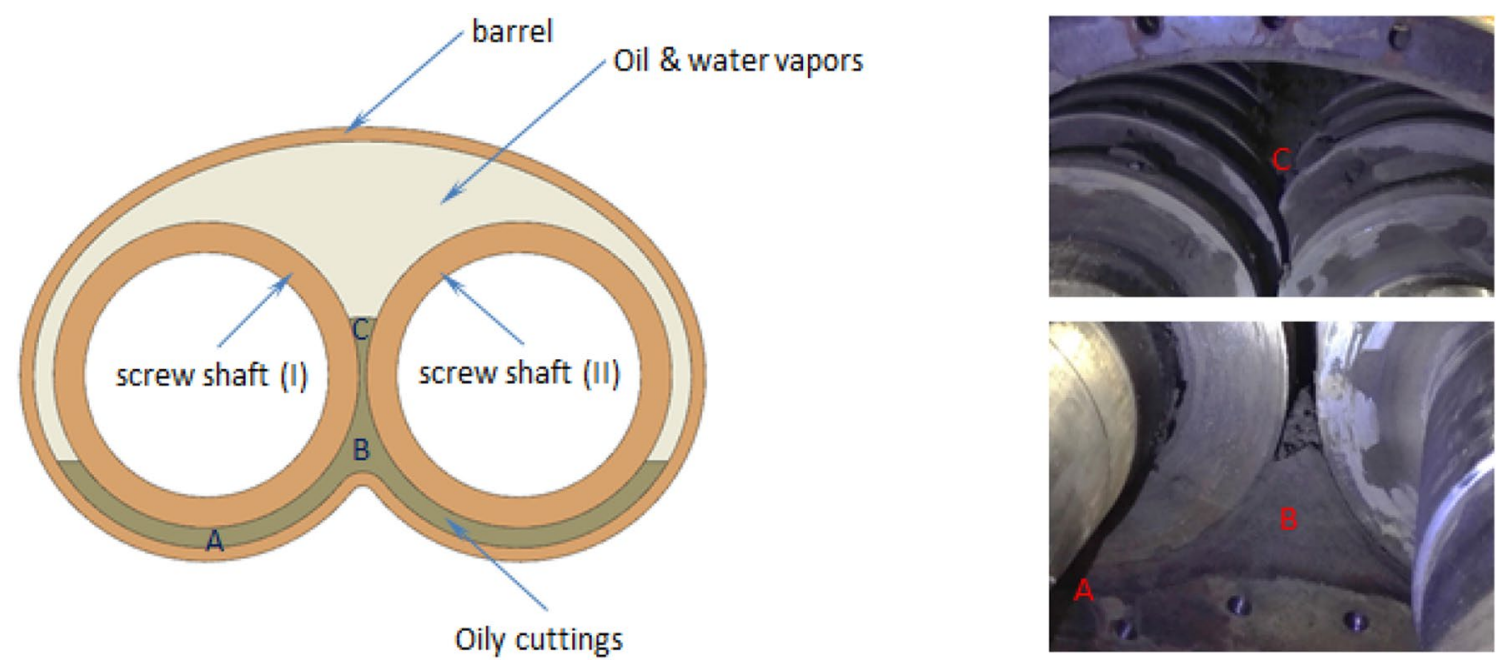

Fig. 6 Distribution of materials in desorption device 


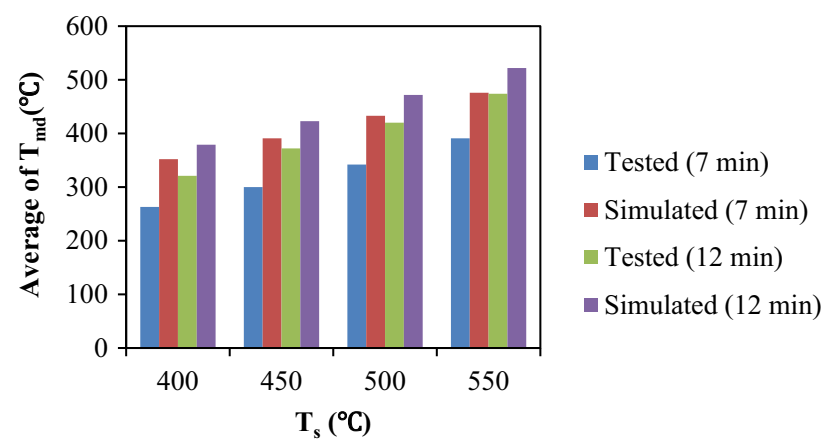

Fig. 7 Comparison of the average temperature of material at TDU discharge port

values are slightly larger than tested results. The deviation between simulated value and tested result is acceptable because that the physical parameters of the samples for the simulation are difficult to match the actual values completely.

Results of material internal temperature distributions are shown in Fig. 8. The materials temperature increase with the heating time expand, while temperatures of different area
('A'/'B'/'C' regions as shown in Fig. 6) are not the same. Temperatures in region ' $\mathrm{A}$ ' and ' $\mathrm{C}$ ' rise faster, and that of region ' $\mathrm{B}$ ' lags behind the other regions. There is a low temperature point in region ' $\mathrm{B}$ ' formed.

At different setting temperatures of heating bed, materials temperature variation curves in three regions are shown in Fig. 9.The results show that the longer the residence time is, the higher the material temperature is closer to the set heating temperature. The change of material temperature in region ' $\mathrm{A}$ ' and ' $\mathrm{C}$ ' are roughly the same, and the two regions temperatures could reach to above $90 \%$ of setting values when the residence time of 12 min. Region ' $B$ ' temperature rise lags behind region ' $\mathrm{A}$ ' and ' $\mathrm{C}$ ', temperatures in this region are only about $55-65 \%$ of the setting values when residence time reach to $12 \mathrm{~min}$, and continue heating to $15 \mathrm{~min}$, that are about $60-75 \%$ of the setting values.

The liquid phase evaporation needs to absorb heat. The material temperature change will become complex when liquid phases are evaporated. In general, the material average temperature rise slows down during liquids evaporation. When the temperature is higher, the deviation between the material temperature and the setting value is greater $\left({ }^{\circ} \mathrm{T} \mathrm{m}^{\prime}\right.$ $\mathrm{T}_{\mathrm{s}}$ ' is smaller). This deviation might become obvious in the
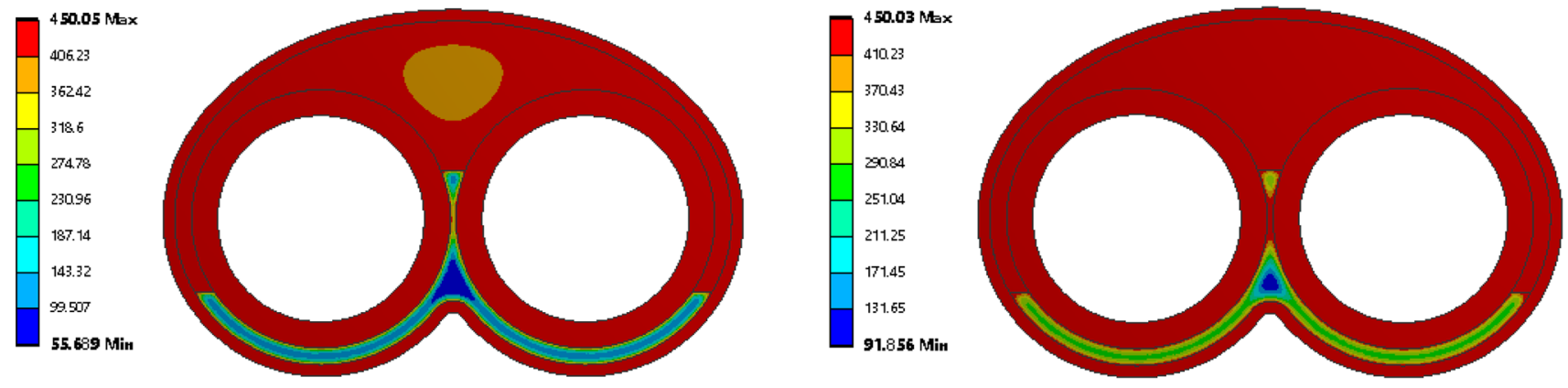

(a) residence time of $1 \mathrm{~min}$

(b) residence time of 4 min
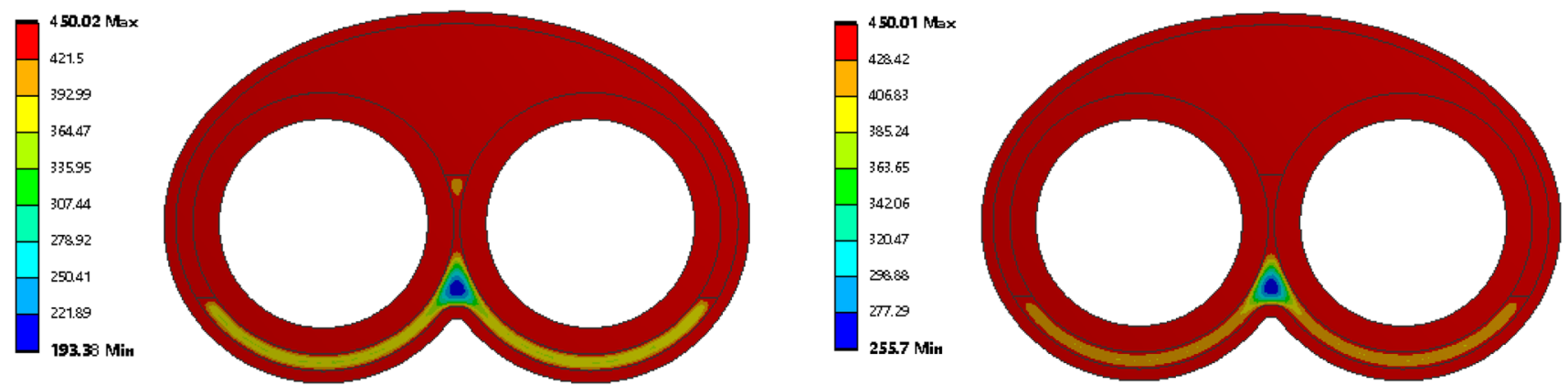

(c) residence time of $8 \mathrm{~min}$

(d) residence time of $12 \mathrm{~min}$

Fig. 8 Temperature distributions in desorption device (setting heating temperature of $450{ }^{\circ} \mathrm{C}$ and screw conveying filling coefficient of 0.44 ) 
(a)

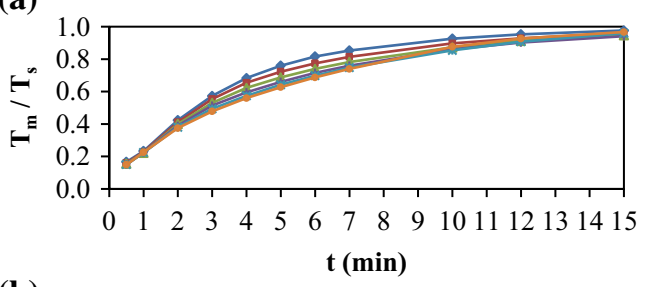

(b)

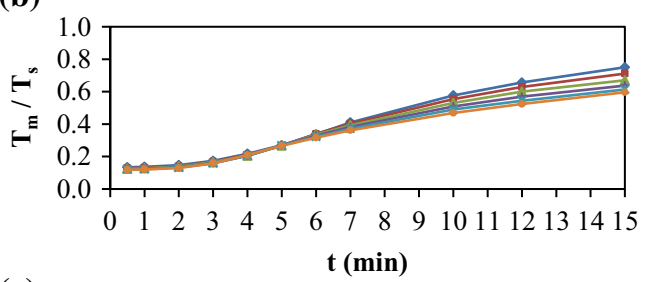

(c)

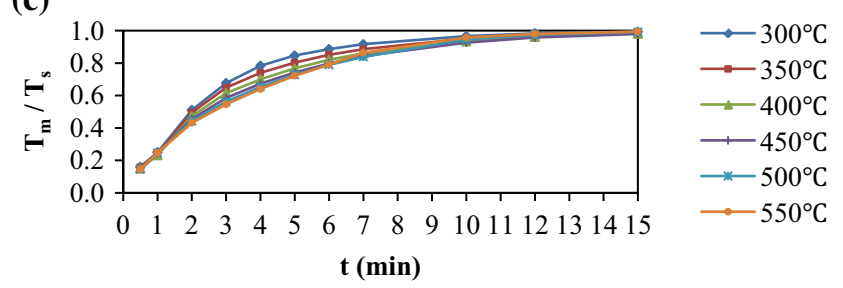

Fig. 9 Temperature changes with residence time (varying curves of region 'A' are shown in $\mathbf{a}$ varying curves of region 'B' are shown in $\mathbf{b}$ and that of region ' $\mathrm{C}$ ' are shown in $\mathbf{c}$ )

main stage of liquid evaporation, as shown in Fig. 9a, c (residence time between 3 and $7 \mathrm{~min}$ ), and in Fig. $9 b$ (residence time more than $7 \mathrm{~min}$ ).

In thermal desorption device, the material accumulation in region ' $\mathrm{B}$ ' is thicker than that of other regions and leads to the region ' $\mathrm{B}$ ' temperature being difficult to reach to the setting value within a limited residence time. Therefore, the oil removal of material in region ' $\mathrm{B}$ ' may not be sufficiently, compared with other regions. By increasing the heating power, the oil of material in region ' $\mathrm{B}$ ' could be removed more thoroughly, but that might be reduced power efficiency. Another way of the improvement is that to adjust the barrel structure of region ' $\mathrm{B}$ ', that is, to reduce the material thickness of region ' $\mathrm{B}$ ' by filling the space gap of this region.

\section{Conclusions}

Thermal desorption experiments of oily cuttings samples were carried out on developed equipment. The TDU adopted electromagnetic induction heating during continuous conveying of materials, and the handling capability was $250 \mathrm{~L} / \mathrm{h}$. Compared with the experimental apparatus in the laboratory, this medium sized experimental system is closer to that of engineering application. The heating temperature can be conveniently controlled by electromagnetic induction heating, and the heating residence time can be adjusted by changing the conveying speed. Disposal effects meet the general requirement (TPH content less than $1 \%$ ) of solid waste disposal in field drilling, and TPH content can be further reduced to $0.3 \%$ by adjusting heating temperature and residence time.

Temperature distribution of materials on filled section of conveyor is not uniform. There is a temperature rising lag area located at the thicker material filling position, in which the material temperature deviates from the setting process temperature in limited residence time, and could lead to incomplete removal of oil contained in materials. Materials in conveyor should be transported in thin layer to avoid the existence of "low temperature area".

The tests show that the electromagnetic heating method is feasible for thermal desorption disposal of oily cuttings, and its advantages are rapid temperature rising and convenient control. Take into account the heating residence time and the thickness of the material conveying layer, the double screws should be designed as a short pitch, shallow groove depth and low speed mode.

Acknowledgements The authors wish to thank Chuanglian (Hubei, China) Petroleum Technology Co Ltd for experimental equipment assembling and providing experimental conditions and technical support.

Open Access This article is distributed under the terms of the Creative Commons Attribution 4.0 International License (http://creativeco mmons.org/licenses/by/4.0/), which permits unrestricted use, distribution, and reproduction in any medium, provided you give appropriate credit to the original author(s) and the source, provide a link to the Creative Commons license, and indicate if changes were made.

\section{References}

Bakke T, Klungsøyr J, Sanni S (2013) Environmental impacts of produced water and drilling waste discharges from the Norwegian offshore petroleum industry. Mar Environ Res 92(11):154-169

Chen C, Li SQ, Yue CT, Kruttschnitt T, Prucker E, Yao Q (2006) Labscale pyrolysis of oil sludge in continuous rotating reactor: mass/ energy balance and product analysis. J Chem Ind Eng (China) 57(3):650-657

Falciglia PP, Vagliasindi FGA (2015) Remediation of hydrocarbon polluted soils using $2.45 \mathrm{GHz}$ frequency-heating: influence of operating power and soil texture on soil temperature profiles and contaminant removal kinetics. J Geochem Explor 151:66-73

Fortuna F, Cornacchia G, Mincarini M, Sharma VK (1997) Pilot-scale experimental pyrolysis plant: mechanical and operational aspects. J Anal Appl Pyrol 40-41:403-417

Jones TGJ, Sanders MW, Chambers BD (2002) Improvements in the analysis of thermally recovered drilling fluid base oils from drilled cuttings. Presented at the SPE international conference on health, safety and environment in oil and gas exploration and production, Kuala Lumpur, 20-22 March 2002, SPE-74166-MS. https://doi. org/10.2118/74166-MS

Júnior IP, Martins AL, Ataíde CH, Duarte CR (2017) Microwave drying remediation of petroleum-contaminated drill cuttings. J Environ Manage 196:659-665

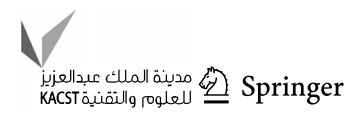


Liu JG, Song W, Nie YF (2008) Effects of temperature on pyrolysis products of oil sludge. Front Environ Sci Eng China 2(1):8-14

Murray AJ, Kapila M, Ferrari G, Degouy D, Espagne BJ, Handgraaf P (2008) Friction-based thermal desorption technology: Kashagan development project meets environmental compliance in drill-cuttings treatment and disposal. Presented at the SPE annual technical conference and exhibition, Denver, Colorado, 21-24 September 2008, SPE-116169-MS. https://doi.org/10.2118/116169-MS

Nickerson R (2008) Indirectly heated screw processor apparatus and methods. Patent: US 2008/0295356 A1 2008-12-4

Petri I Jr, Santos JM, Rossi AS, Pereira MS, Duarte CR, Ataíde CH (2017) Influence of rock chemical composition in microwave heating and decontamination of drill cuttings. Mater Sci Forum 899:469-473

Pierce D, Gaddis C, Wood B (2006) Lessons learned from treating 500,000 tons of oil-based drill cuttings on five continents. Presented at the IADC/SPE drilling conference, Miami, Florida, 21-23 February 2006, SPE-99027-MS. https://doi. org/10.2118/99027-MS

Robinson JP, Snape CE, Kingman SW, Shang H (2008) Thermal desorption and pyrolysis of oil contaminated drill cuttings by microwave heating. J Anal Appl Pyrol 81(1):27-32

Schmidt H, Kaminsky W (2001) Pyrolysis of oil sludge in a fluidised bed reactor. Chemosphere 45(3):285-290

Shen L, Zhang DK (2003) An experimental study of oil recovery from sewage sludge by low-temperature pyrolysis in a fluidised-bed. Fuel 82(4):465-472
Siddique S, Kwoffie L, Addae-Afoakwa K, Yates K, Njuguna J (2017) Oil based drilling fluid waste: an overview on environmentally persistent pollutants. IOP conf. series: materials science and engineering 195(1). https://doi.org/10.1088/1757-899X/195/1/012008

Stephenson RL, Simon S, Robert MC, Edgardo H, Pair RB (2004) Thermal desorption of oil from oil-based drilling fluids cuttings: processes and technologies. Presented at the SPE Asia Pacific oil and gas conference and exhibition, Perth, 18-20 October 2004, SPE-88486-MS. https://doi.org/10.2118/88486-MS

Sun MB, He QS, Liu XL, Wang GB (2017) Discussion on thermal desorption remediation technology with rotary kiln for petrochemical contaminated soil. J Environ Eng Technol (China) 7(5):594-599

Whitney P, Nickerson R (2010) Heat-transferring, hollow-flight screw conveyor. Patent: WO 2010/028008 A1 2010-3-11

Zhu Z, Li J, Xie S, Yuan G (2011) Research and application on resource utilization technology of oily waste drilling fluid. Pet Sci Technol 29(14):1470-1481

Publisher's Note Springer Nature remains neutral with regard to jurisdictional claims in published maps and institutional affiliations. 